\title{
LITERATURA, CENSURA Y MORAL EN EL PRIMER FRANQUISMO
}

\author{
Manuel L. ABELláN \\ (Universiteit van Amsterdam)
}

En toda sociedad que se precie de democrática se dan formas de presión social, de origen vario, que por facilidad de lenguaje podrían incluirse dentro del campo semántico atribuido al concepto de censura. Así, todo grupo social de intetés político común, económico o cultural, en sentido amplio, lucha por imponer a los demás grupos sociales diferenciados, o al conjunto de la sociedad, su específica y particular visión del mundo en lo político, social o económico. Scbre la legitimidad de esta dialéctica de influencias huelga discutir por tazones de pura evidencia: las reglas de juego establecidas en los textos y leyes constitucionales velan por la salvaguardia del dexecho activo y pasivo a la libertad de todo ciudadano y señalan tambiér los cauces por los que han de discurrir las relaciones dialécticas de los grupos sociales en lucha pacífica y semirreglamentada. En un estado democtático todo ciudadano tiene derecho a atender o desechar cualquier reclamo de los grupos sociales formal o informalmente constituidos, cuyo momento de mayor cristalización y transparencia to constituyen las elecciones a los cuerpos representativos: parlamento nacional, autonómico y municipios. Peto la actividad de los grupos y clases sociales no se cancela con los resultados electorales. Las relaciones dialécticas entre grupos y clases, individuos y grupos se prosiguen con altibajos, vehemencia y tensión, independientemente de los momentos de mayor protagonismo, porque la vida social es inconcebible sin la relación dialéctica de grupos y clases sociales. ${ }^{1}$

1. Con la burocratizacion del oficio đe sociólogo parece faber decaído el interés 
Desde la óptica de la convivencia democrática nada impide que determinados grupos o clases intenten ejercer presiones de hecho sobre otros grupos o individuos mediante la difusión o propaganda de su propio ideario. Una entidad editora - periódico, revista, editorial o emisora- escoge y difunde el producto o el mensaje que más le interesa comercial e ideológicamente, a un mismo tiempo, de acuerdo con su propia visión de las cosas, siguiendo su intetpretación del pasado y su prospectiva del futuro. Su tibertad electiva y de acción se fundamenta en el principio de la libertad que asiste a todo grupo social o individuo particular. Dejando de lado el papel específico de los grupos sociales organizados, así ocurre con el crítico literario que selecciona alguna de las obras de un montón: la juzga y mediante su escrito trata de influenciar o convencer, de algún modo, al lector eventual de los méritos del libro reseñado. Esta labor de selección, juicio y difusión la ejercen millones de personas a cada instante, desde el carnicero que selecciona la res y corta el filete hasta el representante de un grupo político. Nadie se insurge contra el ejetcicio de estas libertades ni contra los efectos de las mismas mientras sus consecuencias no conduzcan a una eliminación de las libertades de los demás. Por lo tanto puede afirmarse, sin incurrir en desvario, que to hay sociedad sin «censuras» e incluso podría llegarse a decit que éstas son inherentes a la vida social.

Otta muy distinta cosa es el tipo de censuta ejercido por el gobierno - por la administración. En un estado democrático y pluralista ni ésta ni aquél tienen derecho a constituirse en juez de lo que debe o no debe difundirse porque el primero es meramente parte y la administración del Estado es puro instrumento. Unicamente en los regimenes dictatoriales se da la paradoja de que el gobierno se confunda con el Estado y la nación e intente asumir el papel de juez y parte, anulando moral, política e incluso físicamente aqueilos grupos y clases sociales que disienten de la visión política del grupo que legal o ilegalmente se ha hecho fuerte en el poder, ${ }^{2}$ supeditando el ejercicio de la libertad de expresión a la conformidad con la ideología o preferencias del grupo dominante de hecho.

En España hemos tenido sobrada experiencia de este tipo de intervención censoria durante más de cuarenta años, si se atiende que las limi-

por la sociología dialectizante y dialectizada de Georges Gurvitch. Para sacudirse el encorsetamiento mental es todavía incitante lectura su La vocation actuelle de la sociologie. Vers la sociologie différentielle, París, PUF, 1963.

2. A la experiencia española de este y de los siglos pasados, hay que añadir las experiencias de los fascismos europeos, el exterminio de la intelectualidad, de grupos étnicos en campos de concentración, sin otro motivo que el de haber disentido activa o pasivamente. 
taciones impuestas a la libertad de pensamiento y acción se inician tres años antes de concluirse la guerra civil.

Para tratar de comprender la relación que pueda haber entre la literatura, la moral y la censura hay que tener en cuenta los condicionamientos y circunstancias en los que la censura se impone como medio auxiliar, junto con muchos otros más radicales y efectivos, de depuración política. ${ }^{3}$

Cuando se intenta relacionar, aun siquiera de forma global, los términos de literatura, censura y moral, ocurre casi siempre que el orden o la mera yuxtaposición de dichos términos suscita una cadena de connotaciones falaciosas. Suele pensarse inconscientemente que es obvio que la literatura de la época de la dictadura franquista haya pasado por el tamiz de la censura a efectos de saneamiento moxal y conversión en un producto de consumo que reúna las condiciones indispensables de moralidad. El peligro de moralidad abortado de taíz por la censura previa o la autocensura siempre se supone que tiene que ver con la «inclinación del apetito sensitivo bacia el mal» o concupiscencia, inclinación al mal que puede ser causa, fuente y origen de otros muchos pecados por repetición. ${ }^{4}$

Ahora bien, el tipo de moral que mediante los mecanismos de censura se intenta controlar e imponer -el fin próximo y el fin remoto, según reza la terminología más ortodoxa-- tiene un campo de aplicación que rebasa muy ampliamente el meramente referido a la sexualidad humana. El concepto de moral aquí en cuestión se refiere a la totalidad de las actuaciones propias del hombre, a todos los actas de la voluntad libre, en sus diversos grados de perfección y voluntariedad, todos ellos ordenados a su fin sobrenatural último. Las fuentes de los principios de dicha moral se encuentran en la revelación ctistiana: en la Sagrada Escritura y en la Tradición que completa e interpreta aquélla mediante el magisterio eclesiástico. Fuera de este marco de regulaciones del comportamiento basado en la fe y el dogma, el hombre no tiene salvación porque la luz de la razón sin la fe degenera, se oscurece con las pasiones y no abarca los deberes que impone la revelación para con Dios, para con el prójimo y para consigo mismo. El ministro de Información y Turismo de mayor formación teológica, Gabriel Arias-Salgado, al examinar retrospectivamente la labor realizada en materia de política de la información, afirmaba: «Toda

3. Ei millón de muertos, el deliberado ocuitamiento de las cifras sobre la represión, son prueba contundente de la fiereza fascista. A más de cuarenta años vista de todos aquellos nefastos sucesos, sigue sin haberse podido estudiar el verdadeto alcance de 1 represión.

4. Estos y otros conceptos de doctrina moral se tetoman de un sencillo libro de clase de religión La moral católica, para la escuela y para la vida, Salamanca, Ediciones Anaya, 1960. 
la estructura de situación alcanzada o por alcanzay aún, se apoya en tres basamentos fundamentales:

"1. Existencia de una norma permanente de moralidad objetiva $y$ superior a nosotros mismos, fundada en el derecho natural y en la revelacion.

$₫ 2 .^{\circ}$ Ejercicio de la libertad individual $y$ de las libertades básicas dentro de los justos y naturales limites que impone el becbo de que el bombre es naturalmente sociable.

$3 .^{\circ}$ Servicio al bien comin sin detrimento de los derechos inalienables de la persona bumana.»

La existencia de un orden supetior de moralidad objetiva no era sólo tazón para controlar e imponer normas de moral en las actuaciones de los individuos sino que exan también presupuestos políticos en los que se basaba la forma y la política del régimen: «El Estado es un bien necesario, un bien de carácter instrumental, ordenado próximamente a la concepción plena de la vida social y subordinado al fin último del bombre real e bistórico, elevado al orden sobrenatural de la gracia, y al que el pecado original no daño sustancialmente en su libertad natural. $\rangle^{6}$

Aparentemente, entre moral y literatura parece haber una relación de carácter eminentemente casuístico, según sean las circunstancias que hacen que un producto literatio determinado, en su totalidad o en alguna de sus partes, sea bueno, malo o indiferente desde el punto de vista moral. Las circunstancias y su influjo en la moralidad dependen -en el libro como en cualquier acto humano- de la cualidad de la persona del autor o agente, de la cualidad de la cosa o efecto, de la especificidad del medio empleado, de las razones que han inducido a obrar de tal modo, del grado de voluntariedad e intención y del momento en que se realiza el acto.

Ahora bien, averiguar las circunstancias gracias a las cuales un texto literario, o parte de él, se ha convertido en cosa intrínseca o extrínsecamente buena o mala, o en algo cuya bondad o malicia es únicamente debida al hecho extrínseco de estar prohibido, significaría abrirse camino en terreno pantanoso. Literatura y moral tienen que ver con autor y público, libro y consumidor. Un medio de comunicación impreso que puede llegar a un público potencial y un público concreto que consume y reacciona ante el producto. Las vicisitudes sufridas por un texto literario, previas al libre

5. Gabriel Arias-Salgado, Política Española de la Información, vol. II, Madrid, Ministerio de Informacion y Turismo, 1958, p. 15.

6. Ibidem, pp. 15-16. 
consumo de su lectura por el público, pueden carecer completamente de significación en cuanto a sus circunstancias de orden moral, si bien en alguna ocasión pueda quedar paladinamente demostrada la relación entre el producto de consumo y su carácter motal. La influencia de la concepción moral en la difusión de la literatura, hay que examinarla desde el marco más amplio de las relaciones entre teoría y praxis, ideología y política, cosmovisiones de signo contradictorio, dialéctica entre libertad formal y represión de hecho. ${ }^{7}$

Sobre el propósito, claro y diáano, inicialmente perseguido por los primeros tesponsables de la aplicación de la censura en los albores del régimen franquista, no hay ningún géneto de dudas. Las reiteradas afirmaciones de Franco ante la prensa extranjera coinciden casi textualmente con lás formula* ciones expresadas años más tarde por el impertérrito ministro Arias-Salgado y toda la cohorte de personajes y personajillos, dedicados a vocear las ideas del Caudillo: «Los principios en que se inspira nuestra Revolución Nacional se basan, como ya dije, en la noción de la "persona bumana". Para nosotros, la integridad espiritual y la libertad del bombre son valores intangibles. $Y$ be aquí lo que diferencia también nuestra doctrina de las doctrinas totalitarias que todo lo atribuyen al Estado, es esto lo que da su carácter propio, to que la especifica de las demás doctrinas [... I la concepción del mundo y de la vida. Este carácter católico bastaria para distinguir del estatismo mussoliniano o del racismo bitleriano nuestra Revolución Española que es tha vuelta integral a la verdadera España.»"

El carácter católico del nuevo estado era una consecuencia del análisis sobre los orígenes de los males del país y una condición indispensable para el mantenimiento del nuevo orden social. Así lo entendían los nuevos gobernantes y la jerarqufa católica. El primado de España, cardenal Isidro Gomá, máximo responsable de la redacción de la Carta Colectiva del Episcopado Español, firmada por los obispos españoles, con las honrosas excepciones del cardenal Vidal y Barraquer y del obispo de Vitoria monseñor Múgica, en apoyo a la causa nacionalista, en su pastoral Catolicismo $y$ Patria, conminaba a los gobernantes del momento de este modo: «Go bernantes! Haced catolicismo a velas desplegadas si queréis bacer la patria grande... Ni una ley, ni una cátedra, ni una institución, ni un periódico fuera o contra Dios y su Iglesia en España.»"

7. Véanse algunas consideraciones al respecto en mi libro Censura y creación literaria, Barcelona: Ediciones Penf́nsula, pp. 105 y ss.

8. Citado por Carles Viver Pi-Sunyer, Aproximacio a la ideologio del franquisme en l'etapa fundacional del règim, «Papers» 14, 1980: 32-33. p. 313.

9. Citado por A. de Miguel, Sociología del franquismo, Barcelona, Eutos, 1975, 
«Papers»: Revista de Sociologia

El régimen no había necesitado esperar a esta solemne advertencia para ponerse manos a la obra. Quizás lo único que le había faltado había sido tiempo necesario para llevar a cabo la depuración con rotundidad. Una otden de la Junta de Burgos de 23 de diciembre de 1936 había establecido en su artículo primero: "Se declaran ilícitas la producción, el comercio y la circulación de periódicos, revistas, folletos y toda clase de impresos y grabados pornográficos o de literatura socialista, comunista, libertaria $y$, en general, disolventes.» En su artículo segundo: «Los dueños de establecimientos dedicados a la edición, venta, suscripción o préstamo de los periódicos, libros o impresos de toda clase a que se refiere el articulo precedente, vienen obligados a entregarlos a las autoridades civiles en el improrrogable término de 48 boras a partir de la publicación de esta orden. $^{9}{ }^{9}$ bis Una orden postetior, de 16 de septiembre de 1937, vista la experiencia y las dificultades prácticas que la depuración había planteado en las zonas recientemente ocupadas, establecía: «Las comisiones depuradoras, a la vista de los anteriores indices o ficberos, ordenarán la retirada de los mismos, de libros, folletos, revistas, publicaciones, grabados e impresos que contengan en su texto láminas o estampas con exposición de ideas disolventes, conceptos inmorales, propaganda de doctrinas marxistas y todo cuanto signifique falta de respeto a la dignidad de nuestro glorioso Ejército, atentados a la Unidad de la Patria, menosprecio de la Religión Catolica y de cuanto se oponga al significado y fines de nuestra Cruzada Nacional..$^{\text {to }}$

El equipo de los Servicios de Propaganda y Censura al mando de Dionisio Ridruejo tealizó, en época temprana ya, el censo de las publicaciones periódicas existentes en la zona nacional. Existe un informe imposible de fechar pero que cabe suponer que corresponde a la época del primer gobierno de Burgos en el cual se enumeran las publicaciones de las 25 provincias liberadas hasta aquel momento y en el que figuran 247 publicaciones. Predominan las revistas publicadas por la Iglesia, en su inmensa mayoría boletines parroquiales, hojas diocesanas o publicaciones de asociaciones piadosas. Un número ínfimo lo constituyen algunas revistas profesionales y, el resto, las revistas y periódicos de opinión, son todos órganos de la Falange. A pesar del origen indiscutiblemente moral y favorable a la causa nacionalista de dichas revistas, en la suscinta ficha política elaborada por los funcionatios de aquel servicio sobre los antecedentes del personal directivo de las publicaciones, no escapa a su ojo

9 bis. Ibidem.

10. Gabilán-Alchud citado por Josep Benet, Cataluña bajo el régimen franquista (1a. parte), Barcelona, Editorial Blume, 1979, pp. 249-250. 
avizor e inquisitorial ningún aspecto tocante a la vida privada de las personas. Sobre "Martín Codax», una tevista de carácter religioso y benéfico de Pontevedra, se menciona que si bien la publicación «está en armonía con los postulados que defienden la Causa, tiene en contra a su vicedirector el sacerdote don Emilio Alvarey Martinez, de antecedentes personales y sacerdotales nada recomendables». ${ }^{11}$ Como es natural, este informe exa de carácter estrictamente confidencial, de forma que la información precedente difícilmente pudo trascender más allá del círculo de colaboradores. Como se ve, aun tratándose de figuras pertenecientes a uno de los grupos sociales intocables del nuevo régimen, los aspectos morales tenían importancia y preocupaban a los responsables de la censura.

De la coincidencia de intereses ideológicos y de clase entre la Iglesia y los hombres del nuevo régimen, acaso sea el más trágico ejemplo el concerniente a la actitud silenciadora adoptada por la jerarquía católica a raíz del fusilamiento de 16 sacerdotes vascos y la polémica levantada a este propósito tanto en el mundo católico intetnacional como entre el cardenal Gomá, monseñor Múgica y el presidente de Euskadi, Aguirre. Asombra que frente al prutito de moralidad, Ia jerarquía episcopal -n-que no el gobierno- se callara ante aquel asesinato sacrílego por razones de conveniencia estrictamente política, de coincidencia de intereses ideológicos, puesto que lo importante era la victoria de los nacionales y la negación de la catolicidad y moralidad a los oponentes al Alzamiento Nacional. En su respuesta a Aguirre, hecha pública mucho tiempo más tarde, Gomá llegaba a escribir: «La jerarquia no calló en este caso, aunque no se oyera su voz en la tribuna clamorosa de la prensa o en la arenga politica. Hubiera sido menos eficaz. Pero yo le puedo señalar el dia y el momento en que se truncó bruscamente el fusilamiento de sacerdotes, que no fueron tantos como se deja entrever en su discurso. $Y$ como el lamentable becbo se ba explotado en grave daño de España - nos consta- y conviene dejar las cosas en su punto, yo le aseguro, señor Aguirre, que aquellos sacerdotes sucumbieron por algo que no cabe consignar en este escrito, y que el becho no es imputable ni a un moviniento que tiene por principal resorte la te cristiana, de la que el sacerdote es representante y maestro, ni a sus dirigentes, que fueron los principales sorprendidos al conocer la desgracia. $\gg^{12}$

Mientras por un lado se mantenía el silencio y se insinuaba la justicia de los fusilamientos por algo que no cabía consignar por escrito, nada obs-

11. Véase Censura y creación literaria en España (1939-1976), Barcelona: Ed. Qe* nínsula, 1980, en adelante citado como Censura, pp. 18-19, nota 9.

12. Juan José Ruiz Rico, El papel político de la Iglesia Católica en la España de Franco, Madrid: Editorial Tecnos, 1977, p. 42. 
taba para que, por otro lado, numerosos obispos y sacerdotes clamaran al cielo la sangre de los impíos y réprobos. Fermín de Izurdiaga, sacerdote y falangista, factótum de la revista «Jerarquia» y personaje que durante algunos años fure la eminencia gris de los Servicios de Propaganda y Censura, convirtiéndose más taxde en el interventor general de la Vicesecretaría de Educación Popular, podía escribir: «En la amanecida inmortal España, crecerán espigas de sangre, se amasará con ellas el pan nuevo, que será pan de sangre; y cuando nuestros bijos coman de ese pan sobre la mesa de la Patria, arrojados fuera los cobardes y los sacrílegos, la genteración de nuestros bijos será la generación Nacionatsindicalista invencible y activa; porque toda la tierra de España, palmo a palmo, está teñida de nuestra sangre, que es trigo eterno y semilla fecundadora. ${ }^{13} \mathrm{La}$ significación de la cobardía y lo sacrílego no estaba dictada por normas de moralidad superior sino por pertenencia a uno de los bandos contendientes. La cualidad moral de las actuaciones e inclinaciones humanas era la moral de los vencedores que servía para extirpar los elementos malsanos o degenerados.

Un testimonio de indiscutible valor sobre el carácter primordialmente represaliador de la labor de la censura de libros nos lo proporciona Dionisio Ridruejo en Escrito en España al relatar sus años al frente de la Dirección General de Propaganda, con jurisdicción sobre la edición de libros, cine, teatro, organización de actos públicos y demás actividades de propaganda. «El ejército -dice-- cobraba el poder más decisivo y ejecutivo. La Iglesia se volvía invasora [...] Todo era insatisfactorio: el Partido era una comparsería; la Jefatura del Estado y el Partido -una en la persona- nada tenian que ver entre sí los sindicatos deberian ser una ficción; el Ejército imponía su poder; la Iglesia tiranizaba la politica cultural con criterios calomardianos y proyectaba una autoridad ejecutiva inaceptable sobre la sociedad laica. $\gg^{14}$

En las zonas de la retaguardia la normalización de la vida civil se hacía según las pautas militares y religiosas, tendiendo a convertir a los civiles en mitad monjes y mitad soldados. No preocupaba tanto la preservación de la moral sino la vigilancia y destrucción de cuanto no se ajustaba a la visión político-militar y religioso-social de los nuevos gobetnantes. Dionisio Ridruejo nos señala su profundo estado de decepción y las náuseas físicas que le produjo su participación en la «entrada» de los nacionales en Barcelona. Los camiones de propaganda repletos de ediciones literarias cataianas perfectamente aceptables desde todos los puntos de

13. De Miguel, op. cit., pp. 149-150.

14. Dionisio Ridruejo, Escrito en España, Buenos Aires: Losada, 1962, pp. 17-18. 
vista con la ideología del nuevo tégimen fueron Ilanamente incautados por las autoridades militares. «Las primeras medidas de ocupación -mezcla de bosquedad represiva y beateria empalagosa- me pusieron al borde de la náusea.»

El historiador Josep Benet ha exhumado de la prensa barcelonesa de aquellos días la documentación sobre el desarrollo de la ocupación de Cataluña en un libro que parece haber pasado casi desapercibido pero cuyo valor documental es del máximo interés para comprender el paso de una situación a otra y el carácter represivo de las funciones censorias desde aquel entonces hasta su virtual desaparición. Batcelona quedó sometida a un régimen especial de ocupación dada la complejidad que presentaba el control de una gran ciudad en el orden civil y militar. El bando de ocupación estipulaba la incautación de cualquier medio de comunicación y la puesta a disposición de la autoridad militar de las estaciones radiofónicas, salones de espectáculos con sus instalaciones, imprentas y talleres de grabado y toda clase de existencias de papel y pasta para su fabricación. El artículo $7 .^{\circ}$ ordenaba: «Se inmobiliza también, a mi disposición y con igual probibición, el material impreso y gráfico de todas clar ses, de propaganda política y social, los negativos y las copias de las peliculas cinematográficas y discos gramofonicos. $\rangle^{\text {is }}$ Además, quedaban sometidos al procedimiento sumarísinno de la Jurisdicción de Guerra los delitos realizados por medio de la imprenta u otro medio cualquiera de publicidad y se establecía la censura previa. Estas medidas perentorias, consecuencia y necesidad de un régimen de ocupación militar, se mantendrán inalteradas hasta la Ley de Prensa e Imprenta de 1966.

El plan de ocupación comprendía la eliminación del enemigo mediante la delación, los consejos de guerta sumarísimos, la ejecución de unas trescientas petsonas por semana, ${ }^{16}$ la destrucción, quema e incautación de bibliotecas y archivos públicos y privados y el encauzamiento motal y religioso de la población sojuzgada hasta entonces al servicio de siniestros y mezquinos intereses.

Las bibliotecas privadas y atchivos personales de numerosos intelectuates refugiados en el extranjero fueron destruidos o quemados en la plaza pública. Así ocurrió con los archivos de Antoni Rovira i Virgili o con la biblioteca insustituible de Pompeu Fabra. Las bibliotecas públicas fueron intervenidas y, en el mejor de los casos, sólo clausuradas, como la Biblioteca Pública Arús. A los siete días de iniciada la ocupación se publicaba la siguiente orden: "Las imprentas, librerias, sociedades y particu-

15. Josep Benet, op. cit., p. 216 .

16. Ibidem, p. 230 . 
lares poseedores de libros de tendencia marxista, los recogerán y pondrán a disposición del jefe de Seguridad en el plazo de cuatro dias a partir de esta fecba. El incumplimiento de esta orden se considerará como resistencia al Glorioso Movimiento Nacional.» ${ }^{17}$

La policía puso a disposición de la Cámara Oficial del Libro agentes que pudietan ayudar a la revisión y depuración de todas las libretías. El gremio de libreros ante la pérdida económica que suponía la destrucción pura y simple de las existencias y fondos propuso inútilmente Ia exportación de dichos libros hacia América, alegando las ventajas que resultarían para la Hacienda pública.

A la destrucción de la literatura disolvente vino a añadirse el uso escrito del catalán en todos los ámbitos, e incluso el uso oral. Quedó pro hibido el uso del catalán en la enseñanza del catecismo, en los actos religiosos, plegarias, novenas, sermones. Desaparecieron centenares de publicaciones religiosas, por no citar la desaparición de la prensa en catalán. Sin embargo, la iglesia y su jerarquía se identificaban plenamente con el nuevo gobierno incluso en detrimento de la propia identidad cultutal y lingüística: «[...] Franco, único poder civil español legitimo en su origen y en su actuación, representa y encarna en la guerra que ya ba terminado los sentimientos e ideales que los católicos debemos colocar por encima de todos los demás; mientras que los rojos con su gobierno, tirano en su principio y en su labor, encarnaban y representaban todo lo contrario, o sea los ideales y sentimientos contrarios por completo a nuestra Santa Religión Católica, Apostólica y Romana.» ${ }^{\text {is }} \mathrm{La}$ identificación de la Iglesia con la causa de Franco no se limitaba a una coincidencia giobal, en una comunidad de intereses generales. En la Hoja Diocesana del Obispado de Barcelona del último domingo de abril de 1939 se publica un artículo que no tiene desperdicio, titulado «Lo que quiere Franco y lo que querian los rojos». A pesar de su extensión merece la pena extraer algunos párrafos y resumir fielmente otros. El carácter apodíctico, casi catequético, acentúa su valor como compendio del politicismo ingenuo e integrista que sirvió durante muchos años de pauta a la propaganda franquista en prensa y radio:

Lo que quiere Franco

- España católica.

- Enseñanza del catecismo a los niños. ... Enseñanza contratia a la Ley de Dios.

\section{Lo que los rojos querian}

- Laica y enemiga de 1a Religion Católica.

17. Ibidem, p. 249

18. Ibidem, p. 399. 
- Vida familiar según ei Evangelio.

«Mucbos templos donde se practique el culto católico, [...] donde los buenos españoles reciban los Santos Sacramentos y santifiquen sus almas.»

«Se respete a los señores Obispos y a los sacerdotes que son enviados de Dios, ministros sayos, para enseñarnos el camino del cielo y conducirnos a la gloria eterna.s

- Par y trabajo.

- Justicia social.

- Respeto a la propiedad particular.

- Participación de los beneficios del capital y cel trabajo.

- Vida en cristiana y santa hermandad.

«Defiende la libertad del bombre, que es fruto del cumplimiento del deber para con Dios, para consigo mismo y para los demás.»
- Sujeta a las bajas pasiones y regida «por los mismos instintos de los animales que no tienen uso de razónn.

«Todo lo contrario, y por eso ban profanado todos los templos, incendiándolos en su inmensa mayoria.»

«Querian acabar con todos ellos y por esto asesinaron a todos los que pudieron.s

"Combatiendo de polabra la propiedad privada, robaron $y$ acumularon cuanto pudieron, quedando una gran parte del pueblo sujeta a una borrible miseria, predicaron una distribución de bienes con. tratia a los dictados de la razón.»

«Predicaban una libertad que no es más que el imperio de las pasiones brutales y la tiranis del bombre sobre el bombre.»

Sería un ctaso error dejarse llevar por la indulgencia y considerar este texto producto de una mente infantil, sin más. La praxis política conduce a estos simplismos y necesita de esta ingenuidad para movilizar multitudes sacudiendo resortes itracionales. A pesar de las apariencias este texto es mucho más un decálogo contrastado de los principios que han inspirado la conducta política del franquismo que un producto ingenuo. Cuando algunos años más tarde se distribuya por todo el país, entre los encargados de aplicar la censura, una suerte de "vadetnécum» con las instrucciones a las que atenerse, se les tecordará que hay que «establecer el imperio de la verdad» y difundir las buenas costumbres e ideales que habían inspirado el Movimiento Nacional..$^{19}$ Nadie ignoraba a qué se hać́a clara referencia.

Una vez terminada la conquista militar del país, realizada a fondo la depuración de todo tipo de libros, depuradas bibliotecas públicas y privadas, incautadas las publicaciones de literatura supuestamente disolvente en librerías, editoriales y distribuidoras, efectuada la depuración política de todos los españoles residentes en la zona republicana o en la zona nacio-

19. Censura, pp. 249 y ss. 
nalista, repietas las cárceles de hombres y mujeres, juzgados por hechos, militancia en partidos políticos o por simple simpatía con la República, y, por último, refugiados centenares de miles en el extranjero, difícilmente puede sostenerse que el aparato censorio, Ia organización que debía velar por el imperio de la verdad y la difusión de las ideas que habian inspirado la nueva España, tuviera el menor problema para encarrilar o proteger de la más nimia de las influencias malsanas, desde el punto de vista moral, a cualquiera de sus súbditos.

La moral cristiana, las buenas costumbres, el acatamiento de los deberes del buen cristiano, era lo que diariamente propagaban emisoras de ta. dio y periódicos, al servicio del régimen o complementando la intensa la* bor realizada por sacerdotes o religiosos. Es más, con la incondicional colaboración activa de las autotidades civiles y militares, con el respaldo de todas las fuerzas sociales, se organizaban «misiones» y «cuaresmas», en fábricas y talleres, campos de deportes y plazas de toros, salas de fiestas y locales variopintos, para infundir los principios de la doctrina cristia. na y llamar al arrepentimiento, o al temor de Dios, a aquellos que, pese a las apariencias, estaban todavía demasiado alejados de la Iglesia.

La persistente obsesión por el buen encaminamiento moral y religioso de los españoles no era un deber moral y político de los responsables del nuevo régimen para con sus aliados privilegiados -la Iglesia-- sino también un convencimiento profundo de que el ordenamiento social y político al que se tendía era el que mayores garantías de permanencia del régimen iba a ofrecer, inspirado y acorde con la doctrina de la Iglesia a un mismo tiempo. «El bonor, el gran bonor de nuestro Régimen - dirá en las Cortes su presidente- es y será siempre el de baberse anticipado a todos los otros regímenes con una legislación social que, inspirada en el Evangelio y calcada en las Encíclicas pontificias, representa, para imitar la frase de un gran escritor, el beso de España en las manos de los trabajadoress la dignifica. ción del trabajo, el aumento de los salarios, la retribución de las fiestas, el seguro de entermedad, las viviendas económicas, la protección a las familias numerosas, la participación en los beneficios [...]. España vive en paz... Es boy un pueblo que ora y labora, que reza y canta... La España verda. dera... La España católica por esencia, porqute dejando de ser católica dejaria de ser España. La España social y representativa.» ${ }^{20}$

Partiendo de semejantes presupuestos lo que podía ocurrir $-\mathrm{y}$ en definitiva ocurrió- es que el régimen o sus funcionarios, al convertirse en $\tan$ fidedignos intérpretes de la doctrina moral de la Iglesia, poco a poco la suplantaran en tareas de aplicación y juicio moral reservadas hasta ese

20. De Miguel, op. cit., p. 296. 
momento al cleto y a la jerarquía propiamente dicha. Un tanto de lo mismo iba a ocurrir con el intento de asimilación, por parte del Estado, de las asociaciones de apostolado seglar. Así lo intuía ya el incómodo cardenal Segura en 1938: "Algunos no ban dejado de pensar que con el nuevo estado de cosas, estas asociaciones católico-profesionales son en adelante inutiles porque se afirma que todos, instructores, estudiantes, etc., deberán ser católicos como lo ba decretado el movimiento salvador de España. Se bace necesario declarar que, a pesar de la determinación del nuevo régimen, según la cual en todas las organizaciones debe dominar el espiritu religioso patriótico, la necesidad de estas asociaciones subsiste, no obstante, con toda su fuerza, más todavia quizá que en los tiempos que precedieron. ${ }^{21} \mathrm{De}$ forma radicalmente distinta a la empleada por el cardenal Segura - documento pastoral públicom, pero plenamente coincidente en el fondo, se dirigía el cardenal Isidro Gomá en carta personal a Franco para señalarle que la Ley de Prensa de 22 de abril de 1938 ponía en tela de juicio la lealtad de la prensa católica a los poderes reconocidos, al someter a escritores de plena solvencia política y moral a la tutela y vigilancia de la censura, habiéndose incluso dado el caso de que en aplicación de la censura se había llegado a prohibir textos de las mismas autoridades eclesiásticas, que habían sido ya publicados. ${ }^{22}$ Esta continua tensión entre la Iglesia y el régimen era inevitable y explica el tratamiento de excepción que recibió la Iglesia y su clero mientras hubo perfecta o consensuada comunidad de intereses. Explica también parte del papel que los criterios de orden moral jugaron en la aplicación de la censura.

Vistas las condiciones políticas y sociales creadas tras la depuración y el aniquilamiento físico de todo simpatizante con la situación anterior, resulta imposible imaginar transgresión alguna de las normas de moralidad eñ ningún ámbito público y menos aún en un medio de difusión como el libro sometido hasta 1966 a la censura previa obligatoria. Sólo podían plantear algún problema las reediciones de libros anteriores al triunfo franquista $\circ$ las obras de autores editados en el extranjero, fueran tefugiados políticos o escritores de otros países.

Los informes de censura de la época de Burgos dejan claramente entrever que cuando la dificultad principal radicaba en los aspectos morales de la obra es que se trataba de libros para teedición. Y lo mismo ocurría con las dificultades con que tropezaban libros escritos con total libertad con respecto al dogma católico, en épocas anteriores, en las que éste era una de

21. Juan José Ruiz Riç, op. cit., p. 69.

22. Véase en Censura, p. 45 i ss., el procedimiento seguido por el Primado Pla y Deniel en estas materias. 
las opciones posibles dentro del abanico de creencias. Jugaba también un papel la actitud beligerante o de simpatía de! autor del libro hacia la nueva situación política. El sencillo esquema por el que se guiaban los censores para la redacción de sus informes confirma lo anteriormente dicho: «1) ¿Ataca al dogma?, 2) ¿a la moral?, 3) ¿a la Iglesia o a sus ministros?, 4) ¿al régimen o a sus instituciones?, 5) ¿a las personas que colaboran o ban colaborado con el régimen?, 6) los pasajes censurables, ¿califican el contenido total de la obra?"

Si se tevisan algunos de los informes de esa época se verá que un libro presentado a teedición, de Gregotio Marañón, Raíz y decoro de España, tropieza con problemas de orden dogmático más que moral tocantes a las ideas del autor sobre la eugenesia. Curiosamente, el propio censor hace referencia al hecho de que dicha obra «se pudiera baber publicado en otro estado de cosas $y$, entonces, al editor le bubiera sido fácil no corregir el originals. ${ }^{23}$ Sobre la actitud personal de Gregorio Marafión frente al régi* men no cabe hacer ninguna observación, si se tiene en cuenta que este personaje liberal había colaborado activamente a la huida de Ramón Serrano Suñer de la capital de la España republicana. Muchos más problemas tuvo y siguió teniendo durante largos años la producción literatia de Pío Baroja, considerada literatura disolvente en máximo grado. Esta severidad sólo cabe explicarla por la conocida actitud anticlerical de don Pío y no por el carácter moral deletéreo de sus novelas. «Impío, clerbfobo y desbonestos son los calificativos aplicados a la totalidad de su obra. Si hu. biese que citar un caso paladino de transgresión de la moral y las buenas costumbres éste sería el de las novelas de Jardiel Poncela: «El am. biente total de la obra, sin ser grosero, es de una inmoralidad continua, adobada con la gracia y el bumor peculiar del autor.» La propuesta del censor consistió en la adaptación del texto «al ambiente y vida española del momento presente», tarea en la que Jardiel Poncela sobresalió, hay que reconocerlo, vistas las correcciones efectuadas en varias de sus novelas. ${ }^{24}$ Las demás dificultades de las reediciones estaban en relación directa con la rigidez o fexibilidad de las nuevas pautas políticas. Se suprimió el prólogo y una veintena de páginas de El Periquillo Sarniento porque el texto de Fernández de Lizardi podía interpretarse como antagónico de las ideas de la Hispanidad y del Imperio. Seguramente debido también al antagonismo de la

23. Este $y$ otros fragmentos de informes de la censura están sacados de una antología inédita todavía de documentos de los Atchivos de la Censura, titulada Sobre censura. Documentos (1939-1976), en busca de editor.

24. Op. cil. 
persona del intelectual mejicano Alfonso Reyes, su nombre quedó eliminado del ptólogo al Libro de Buen Amor.

La autocensura, el peligro de la represión, el temor razonable a ser considerado como elemento insolidario con la nueva situación, fueron motivos más que suficientes para que el grupo de hombres intelectualmente selectos encargados de aplicar la censura, se dedicara más a preferir una palabra por otra y, si se terciaba el caso, a hacer crítica literaria, que a expurgar obscenidades. Los comités o equipos de depuración habían realizado su tarea. ${ }^{25}$

En 1942, la novela de Susana March, Una alondra en la casa, es calificada «del género rosa mas no de primera mano, sino de imitación, es decir, inferior en valor literario $y$ superior en necedad $y$ carencia de sustancias. Tres años más tatde, los censores no ven nada inmoral en la novela del primer Nadal, lo cual no podía ser novedad realmente. La revista «Destino», subtitulada «Política de Unidad», germen de la editorial que otorgaba el premio literario, había sido creada en Burgos bajo los auspicios de FET y de las JONS y con el apoyo financieto de la Sección de Propaganda y Censura. No extrañe que el juicio del censor se centre en lo literario: «Novela i $\hbar$. sulsa, sin estilo ni valor literario alguno.» Ramón Ledesma Miranda pasaba por el mismo cedazo al presentar Antes del mediodia: «No bay en la novela gran finura ni el estudio psicológico es de gran profundidad. La obra está llena de unos cuantos conceptos de filosofía barata y de unos cuantos tópicos manidos y vulgares.»

La labor realmente hercílea de los censores no fue la de la censura de libros durante esta época, sino el control censorio previo de la prensa, radio y cine. El control de las noticias, la censura de los textos a punto de pasar por la rotativa, la redacción de las consignas, su envio y la comprobación a posteriori de que la tónica general del periódico se había o no ajustado a las directrices telegrafiadas. Tener sujeta la comunicación oxal por medio de la radio, evitar las improvisaciones en un medio de comunicación directa. Revisar cientos de películas extranjeras, concebidas y realizadas para una sociedad pluralista en gustos, dogmas religiosos o moral. Cerciorarse que las distribuidoras y los directores de las salas de cine habían sido escrupulosos en el «pase» de los cortes. Un auténtico ejército de delegados locales, miles de personas, a disposición. Estas tareas unidas a Ias del necesario control de los espectáculos públicos, teatro, cabaret, reuniones deportivas, asambleas de asociaciones, actos académicos o de docencia universitaria fueron la labor realmente ingente de quienes intentaron crear una sociedad a su imagen y semejanza.

25. Véase la documentación exhumada por Josep Benet en el libro citado antetiormente. 
Claro está que todo escritor novel -acudiera con su primer o segundo manuscrito- iba a topar alguna vez con la incomprensión, desconfianza o testarudez del censor de tumo. Pero lo más curioso ocurrido con censura durante estos primeros años es que fueran precisamente escritores de inquebrantable adhesión al régimen quienes protagonizaran los conflictos con el aparato censorio, ya fueta con anterioridad o posterioridad a la publicación de algunas de sus obras. Curioso, aunque nada extraño, es también que hayan sido algunos de estos escritores quienes, pasados los años, hayan podido deleitar al público con la teproducción de informes censorios a cual más sañudo. Así, las peripecias de La familia de Pascual Duarte o La colmena, de Camilo José Cella; La quinta soledad, de Pedro de Lorenzo; Javier Mariño, de Gonzalo Tortente Ballester; La fiel infanteria, de Rafael García Serrano. Examinado todo ello con más detalle se desvanece la extrañeza. El primero, era censor de revistas y no, como ha afirmado recientemente, del «Sagrado Corazón de Jesús», ${ }^{26}$ sino de publicaciones literarias también. El segundo, to que es cierto es que en la década de los años cincuenta ejercía todavía de censor, con un ardor que iba mucho más lejos que el del propio director general, Pérez Embid. ${ }^{27}$ Sobre el tercero baste recordar que formó parte de la Delegación Nacional de Propaganda en Burgos. A propósito del último basta con leer la novela secuestrada para conocer sus posturas políticas. ${ }^{28}$ A excepción de la identidad política e ideológica que a todos los unía, lo que podía separatlos, el único o uno de los pocos puntos de discrepancia entre dichos autores podía consistir - como puede parecer natural, a fin de cuentas- en sus respectivas inclinaciones o hábitos del «apetito sensitivo hacia el mal», si no resulta enojoso el uso de una fórnula propia de los manuales de moral cristiana. Identificados también en todo lo que se hacía para el saneamiento moral y político desde el aparato censorio, estos escritores/censores fueron personas mentalmente capaces y preparadas para transgredir, lo que no era esencial al nuevo régimen y sólo un filtro para medir el grado de lealtad al régimen entre los sospechosos: la moral. Abora bien, después de la depuración llevada a cabo, el único terreno en el que cabían desavenencias, fuera de los cenáculos franquistas en sus diversas gamas, era el de la moral y las buenas costumbres. El triunfo militar de los nacionales sobte los republicanos no había implicado un cambio de piel en sus incondicionales. En caso de tzansgresión pública de los principios mora-

26. Recientes declaraciones hechas en el suplemento del «País SemanaI».

27. Véase Censura, pp. 113, 162 y 167.

28. Véase también Ia documentación al respecto presentada por J. M. Martínez Cachero, Historia de la novela española entre 1936 y 1975, Madrid: Editotial Castalia, 1979, pp. 101 y ss. 
les había siempre una hipotética reacción de la Iglesia, y en caso de producirse, era beneficioso para el régimen someterse a ella. Además, los asesores religiosos pertenecientes a la plantilla de censores velaban, dentro del margen de lo opinable, por la eliminación de cuanto fuese periudicial.

Mientras duró el aislamiento de la sociedad española respecto a los demás países, el llamado período autártico, fue relativamente eficaz mantener el cordón sanitario que impedía cualquier manifestación de la cultura contraria a presupuestos de una extrema moralidad. Peto el mundo y Europa cambiaron, Las naciones europeas reanudaton sus relaciones diplomáticas, se abrieron paulatinamente las fronteras, se establecieron ciertos contactos, el liberalismo inspirador de las sociedades democráticas, aunque malsano a los ojos del franquismo, era preferible al até́smo comunista -punto en el que coincidian el franquismo y las democracias occidentales-. Si los españoles no viajan al extranjero, los turistas europeos comenzaron a frecuentar las playas. La primera oleada de turismo masivo fue el turismo religioso con motivo del Congreso Eucarístico Internacional de Barcelona. Muchos jóvenes y adolescentes que no habían vivido la guerra civil o no guardaban ningún recuerdo de ella descubrieron que ni la fe católica ni la práctica motal etan cosas monolíticas. Había otras formas aceptadas y aceptables de compaginar fe, moral y democracia. El lavado de cerebro empezó a perder eficacia, para algunos el mundo se tambaleó, dejó de tener rigidez y vinieron un sinfín de crisis personales, en gente adulta y gente joven. EI contraste - aunque fuera indirecto o de segunda mano- entre el progreso económico en los países europeos y la persistente miseria, las migraciones del campo a la ciudad, la creciente marginación social, el inmenso chabolismo del suburbio, la distancia entre las palabras y los hechos, el engreimiento bombástico de los hombres afines e incondicionales al tégimen, todo ello contribuyó a que se agtieta* ran los muros de contención levantados sobre la «la bosquedad represiva y la beatería empalagosa» señaladas por Dionisio Ridruejo.

$\mathrm{Si}$ el tégimen habia tenido que abrir el país al primer turismo, los responsables de la censuta trataban de mantener la cerrazón más férseamente que nunca frente a la avalancha de libros de importación editados en la América Hispana o libros de la literatura extranjera destinados a la traducción. Estudios de la índole como el de Ricardo Gullón sobre La poesía de Luis Cernuda eran rechazados por el censor/escritor Pedro de Lorenzo: «...exaltación de un autor que se manifestó comunista en la Antología de 1934 de Gerardo Diego, que ba combatido públicamente al Régimen y con. tinúa en el exilio manifiestamente bostil. No se trata de tachaduras... sino del problema de resolver sobre la apología de una figura y una temática declaradamente enemiga de los principios religiosos: es blasfematorio; mo- 
rales: es uranista; politicos: es rojo de España.» André Maurois veía condenada a edición de lujo su obra El instinto de la felicidad y a Borges se le prohibía la edición de sus Ficciones. Sin embargo, todo escritor español medianamente sensato sabía que transigiendo en los detalles, en las minucias, dejando a los censores intacto el placer de creerse omnimodos y prepotentes, aceptando «seno» por "pecho», o viceversa, las novelas salían adelante siempre y cuando, globalmente considerado, el escritor fuera de fiar y no levantara sospechas de hostilidad hacia el régimen. La noria de Luis Romero: "Serie de cuadros con un largo desfile de personajes apenas enlazadios entre sí. El autor describe en breves pinceladas $y$ con pensamientos intimos de cada personaje, la vida y los problemas de cada uno. Abundan los tipos de gente de mal vivir: invertidos, prostitutas, etc., $y$ en toda la obra bay la preocupación constante del problema sexual, expues. to con crudeza y desenfado. Creo que su lectura puede resultar francamente perniciosa para una gran mayoría de lectores.» ${ }^{29} \mathrm{La}$ novela se publicó sin cortes, prácticamente.

Algunos af́os después, a fnales de la década, los grandes problemas que encuentran la narrativa y la poesía no son ya problemas de moral, sino de elucidación del carácter político y trasfondo ideológico. La censura sigue haciendo hincapié en lo pernicioso para el público lector desde el punto de vista moral. Sin embargo, un examen detallado de los casos más candentes de aquellos años nos revela que detrás de la máscara del puritanismo moral se esconde el hábito y el irreprimible deseo de castigar al enemigo potencial. ${ }^{30}$ ¿Qué había ocurrido entre el momento de máxima y total compenetración entre la Iglesia y el régimen y el final de los años cincuenta? En apariencia, uno de los aspectos importantes de la aplicación de la censura había sido el de la moral. Tan sólo en apariencia importante puesto que el régimen había becho uso de los métodos más expeditivos que imaginar se pueda para cortar de ráz cualquier resabio de la situación anterior. Al haber acotado Iglesia y régimen las esferas tespectivas de influencia y reconocido la plena soberanía de ambos, el punto de contacto entre las cuestiones puramente espirituales y las cuestiones mixtas, o indirectamente relacionadas con el orden dogmático, era el ámbito de lo moral. El régimen asegurando la aplicación de este último se granjeaba el apoyo social de la Iglesia y, de este modo, ésta lograba ejercer su influencia en el terreno político mediante la moral. Lo que estaba en juego era el equilibrio de la coexistencia de dos fuetzas que coincidian en una visión ideológica común.

29. Sobre censura, op. cit., passim.

30. Censura, pp. 120-136. 
En la primavera de 1954 se inicia una controversia cuyo trasfondo ha sido poco estudiado desgraciadamente. Contrariamente a lo que pudiera haberse esperado, no fueron discrepancias en el terreno de la moralidad pública o privada lo que condujo a una grave crisis de confianza entre el régimen y las autoridades eclesiásticas. A raíz de la publicación en «Ecclesia» de un artículo titulado «IV Congreso Internacional de Prensa Católica. Reflexiones de un participante», artículo escrito a título personal por el director de este órgano de expresión del episcopado, se desataton las iras del ministro de Información y Turismo, Gabriel Arias-Salgado. Éste, desde las páginas de «El Español», hizo gala de sus conocimientos teoló gicos y esclateció algunos puntos poco definidos de la doctrina franquista sobre política de la información. Las posturas y opiniones atacadas sirvieron para perfilar el pensamiento doctrinal en el que se había articulado la política de censura de libros y prensa hasta ese momento. El esfuerzo de clarificación realizado puede calificarse de excepcional. Excepcionalidad debida también a la envergadura de los participantes en aquel insólito debate público entre autoridades del tégimen y autoridades eclesiásticas.

Para el ministro Arias-Salgado las ideas vertidas por el autor del artículo sobre el peso de la censura estatal, la política de consignas a los peribdicos, la existencia de la censura previa y la filtración de noticias por los funcionarios del Estado eran afirmaciones equívocas, objetivamente falsas y mortíicantes para el Estado español y también, al menos de hecho, para la jerarquía eclesiástica. «De su intención [...] no queremos, ni po. demos, ni debemos juzgar. De las palabras escritas, que ban sido divulgadas entre los numerosos lectores de su revista, si tenemos que afirmar que no son procedentes ni responden a la realidad. Las relaciones entre el Estado nacido de la Cruzada y la Iglesia fueron siempre las que corresponden a un Estado realmente católico; nunca bubo confusión de ambas esferas y las relaciones fueron cordiales en todo momento. $\$^{31}$

El director de «Ecclesia», Jesús Itibarren, había puesto de relieve los progresos que la prensa católica había logrado haciendo pleno uso de la libertad de expresión en países en los que el Estado no detentaba monopolio alguno. La situación española se le antojaba anómala puesto que el régimen reconocía la total soberanía de la Iglesia. Difícilmente podía entenderse en el extranjero que un país que se proclamaba católico «no encuentr $[e]$ ciento quince bombres con patriotismo, sentido común y espiritu de responsabilidad a quienes poder encomendar con autonomía la dirección de un periódico dentro de los cauces de una ley clara y bonrosa. Raro

31. Gabriel Arias-Salgado, Textos de Doctrina y Politica de la Informacion, Madrid: Secretaría General de1 Ministerio de Información, 1956, p. 163. 
es que no pueda confiarse en un centenar de directores $y$ sí en una cin. cuentena de censores, no superiores a aquéllos por ningún valor bumanos.

Con el aplomo propio de quien sabe el terreno que pisa, doctrinalmen. te hablando, la réplica del ininistro venía a subrayar que en la concepción española de la prensa como institución social, ésta no era sino instrumento al servicio de los intereses de la comunidad para librar a la nación de la servidumbre de los grupos de presión. El liberalismo condenado por la Iglesia «levantó el gran sofisma de identificar en todos los ordenes la libertad del ciudadano con la libertad frente al Estado. Llegó a persuadir al bombre de que el Estado es el linico enemigo de su libertad. Esta falacia persuasiva fue igualmente utilizada por las izquierdas revolucionarias $y$ por las derecbas conservadoras en beneficio de los poderes económicos que quedaron dueños del campo y únicos y exclusivos beneficiarios de la libertad. ${ }^{33} \mathrm{La}$ libertad de expresión —-mejor libertad de divulgacióndebía quedar sometida a la verdad, ya que, para el error y el mal no hay libertad. Y si se diera el caso de errat o de abrazat el mal, se trata no de la perfección de la libertad humana sino de su imperfección y sus limitaciones.

Desóe el punto de vista de la doctrina católica no había nada que oponer a la censura cuyo origen era eclesiástico y anterior incluso al descu" brimiento de la imprenta. El régimen reclamaba pata sí el reconocimiento del principio de prudencia en la aplicación de la censura. Aceptaba la libertad para to bueno y lo verdadero, ninguna para el error y el mal: «Esia es la norma permanente, esta ley que llevamos impresa en nuestra naturaleza; éste es el principio estable y regulador, aun cuando, en deter. minadas circunstancias, puede la prudencia politica tolerar el mal o permitir el error, siempre que se evite un mal mayor o se conserve un mayor bien y siempre por causa del bien común y por las exigencias del bien pú. blico. $\$^{34}$ Dicho en otras palabras, la unión de las espadas y el altar, la con. nivencia de intereses quedaba intacta mientras otros males mayores no la pusiesen a prueba. La jerarquía daba a entender que deseaba cierta auto. nomía de vuelo y el contrato tácito entre los dos quedaba en ciertos aspectos aruiado. La moral se relajaba y el régimen estaba dispuesto a permitir el error siempre y cuando se evitara el mayor mal: el debilitamiento de su autoridad.

32. Ibidem, p. 372.

33. Gabriel Arias-Salgado, Politica española de la Información, II Antologia sistemática, Madrid: Ministerio de Infotmación y Turismo, 1958, p. 60.

34. Ibidem, p. 59. 